\title{
Mechanistic studies of copper(II)-mediated oxidation of vic-dioxime to furoxan
}

\author{
OINDRILA DAS and TAPAN KANTI PAINE* \\ Department of Inorganic Chemistry, Indian Association for the Cultivation of Science, \\ 2A\&2B Raja S C Mullick Road, Jadavpur, Kolkata 700 032, India \\ e-mail: ictkp@iacs.res.in
}

\begin{abstract}
The oxidation of vic-dioximes to furoxans by copper(II) perchlorate in acetonitrile as the oxidant has been discussed. This method was found to be applicable for a broad range of vic-dioximes. Copper complexes of 1,10-phenanthroline derived furoxans were isolated by oxidation of the corresponding copper(II) complexes of 1,10-phenanthroline based dioximes. In exploring the mechanism of copper(II)-mediated oxidative cyclization of vic-dioxime, a transient blue species was observed in the reaction pathway. Based on the spectroscopic signatures and reactivity patterns, the intermediate was proposed to be a dioximatecopper(II)-dinitrosoalkene complex. These results along with the role of metal ion and solvent in the oxidative transformation reaction are discussed in this review.
\end{abstract}

Keywords. Copper; vic-dioxime; oxidation; furoxan; 1,10-phenanthroline, dinitrosoalkene.

\section{Introduction}

Furoxans (1,2,5-oxadiazole-2-oxides) are fivemembered heterocycles and exhibit nitric oxide (NO) donor activity. ${ }^{1}$ Furoxans and benzofuroxans, therefore, find useful applications in medicinal and biological chemistry (figure 1). ${ }^{2-7}$ In synthetic chemistry, furoxans are used as intermediates for the synthesis of important heterocyclic molecules. ${ }^{6}$

Furoxans are normally prepared by oxidative cyclization of vic-dioximes. Many different oxidizing agents such as hypohalite, ferricyanide, ceric ion, nitric acid and nitrogen oxides, manganese dioxide, lead tetraacetate, $N$-iodosuccinimide and phenyliodine(III) bistrifluoroacetate have been used for the two-electron oxidative cyclization reaction. ${ }^{8,9}$ Benzofuroxans can also be synthesized by thermolysis of ortho-nitroaryl azides and by oxidation of ortho-nitroanilines. ${ }^{8}$

Recently, we have used copper(II) salts in acetonitrile in the oxidation of vic-dioximes to corresponding furoxans. ${ }^{10}$ Copper(II) salt in acetonitrile, a strong oxidant, is able to oxidize a wide range of vic-dioxime substrates (alkyl, aryl, and alicyclic and heterocyclic dioximes) in high yield under ambient conditions (scheme 1). The oxidant gets reduced to tetrakis(acetonitrile) copper(I) in the redox reaction. Two equivalents of copper(II) salts are needed for optimum yield of the furoxans. We present here a review

*For correspondence of our work on the mechanistic studies of copper(II)mediated oxidation of 1,2-dioximes to furoxans.

\section{Oxidation of vic-dioximes}

The oxidation of vic-dioxime to furoxan involves the transfer of two electrons and two protons. However, little is known about the mechanism of this oxidative cyclization reaction. It was proposed that a vic-dioxime gets one-electron oxidized to an iminoxyl radical followed by further one-electron oxidation to oxoimmonium cation during the electrochemical oxidation. ${ }^{11}$ The two-electron oxidized species then undergoes cyclization to form furoxan. To understand the mechanism of vic-dioximes oxidation using $\mathrm{Cu}^{2+}$ in acetonitrile as the oxidant, we have recently reported the oxidation of 1,10-phenanthroline-based dioximes (scheme 2). ${ }^{12}$ The furoxans derived from 1,10-phenanthroline dioximes have the ability to form copper complexes (via chelation through nitrogen atoms of phenanthroline ring) and copper ions may stabilize some intermediate species during the electron transfer reactions.

The formation of 1,10-phenanthroline furoxan $\left(\mathrm{L}^{3}\right)$ and 2,9-dimethyl-1,10-phenanthroline furoxan $\left(\mathrm{L}^{4}\right)$ has been established crystallographically by single-crystal $\mathrm{X}$-ray structure determination of the corresponding copper complexes. ${ }^{12} \mathrm{X}$-ray single crystal structure of $\left[\mathrm{Cu}\left(\mathrm{L}^{3}\right)_{2} \mathrm{Cl}\right]\left(\mathrm{ClO}_{4}\right)$ (2), prepared by mixing the precursor dioxime $\left(\mathrm{H}_{2} \mathrm{~L}^{1}\right)$ with copper(II) chloride and 


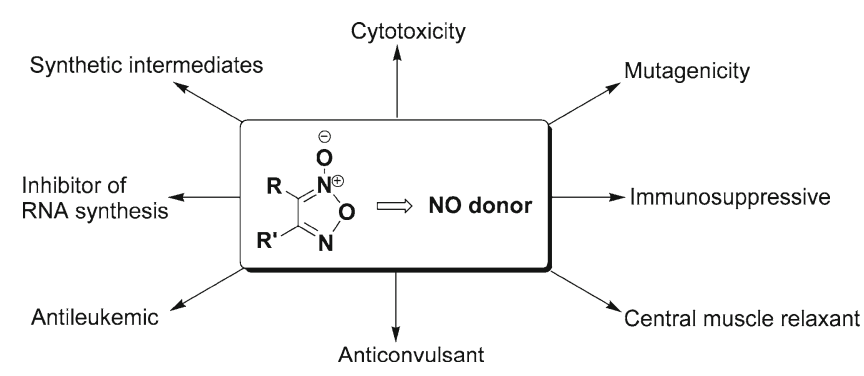

Figure 1. Applications of NO donating furoxans.

sodium perchlorate in acetonitrile, reveals a mononuclear five-coordinate copper complex (figure 2). The metal ion in the monocationic complex resides in a distorted square pyramidal coordination geometry ligated by two bidentate $\mathrm{L}^{3}$ ligands and one chloro ligand. The formation of furoxan ring in $\mathbf{2}$ is clearly evident by structural comparison with the corresponding dioxime complex $\left[\mathrm{Cu}\left(\mathrm{H}_{2} \mathrm{~L}^{1}\right)_{2}\left(\mathrm{H}_{2} \mathrm{O}\right)\right]\left(\mathrm{ClO}_{4}\right)_{2}$ (1). The dicationic complex $\mathbf{1}$ displays the five-coordinate distorted trigonal bipyramidal coordination geometry at the metal ion. The $\mathrm{N}-\mathrm{O}$ bond distances in complex 1 are in the range of 1.347(9)-1.379(9) $\AA$ typical for oxime groups. ${ }^{12}$ On the other hand, three different bond lengths for $\mathrm{N}(5)-\mathrm{O}(1), \mathrm{N}(6)-\mathrm{O}(1)$ and $\mathrm{N}(6)-$ $\mathrm{O}(2)$ of the five-membered ring in 2 are 1.337(7), $1.427(8)$ and 1.182(7) $\AA$, respectively, indicating a heterocyclic ring fused at positions 5 and 6 of 1,10phenanthroline. ${ }^{13}$ The metal-ligand bond distances in both 1 and 2 suggest the +2 oxidation state of copper ion. X-ray crystal structure of $\left[\mathrm{Cu}\left(\mathrm{L}^{4}\right)_{2}\right]\left(\mathrm{ClO}_{4}\right)$ (3) further provides evidences for the formation of furoxan ring. Furoxan $\mathrm{L}^{4}$ is formed in the oxidative transformation of the dioxime $\mathrm{H}_{2} \mathrm{~L}^{2}$ by copper(II) perchlorate in acetonitrile. The structure reveals a mononuclear copper(I) ion in a distorted tetrahedral coordination geometry. Upon binding with the metal ion, two 2,9-dimethyl-1,10-phenanthroline furoxan
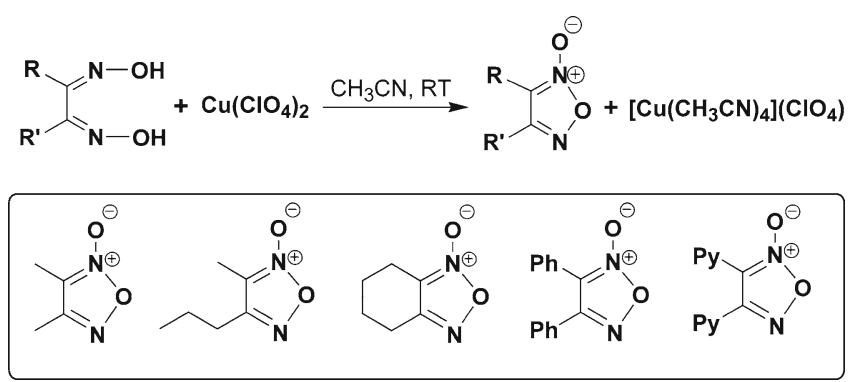

Scheme 1. Oxidation of vic-dioximes to furoxans by copper(II) perchlorate in acetonitrile. List of furoxans synthesized from the corresponding dioximes by this method (below).

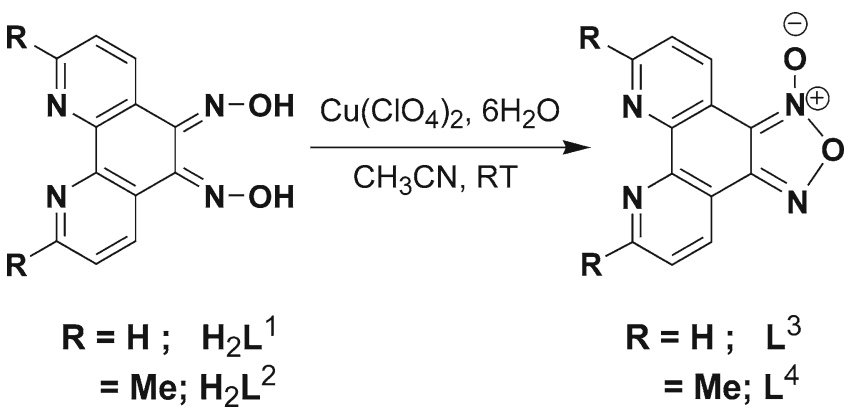

Scheme 2. Oxidation of vic-dioximes derived from 1,10phenanthroline.

ligands are perpendicularly oriented, maintaining minimal steric repulsion between the four methyl groups on ligand backbone. ${ }^{12}$ The composition of complex 3 further supports the reduction of copper(II) to copper(I) during the oxidative transformation of vic-dioxime to furoxan.

\section{Mechanistic studies}

No intermediate species was observed at room temperature during the oxidation of vic-dioximes that do not have any coordination site other than oxime groups. On the other hand, a transient blue intermediate with a charge transfer (CT) band at $608 \mathrm{~nm}$ in the optical spectrum was observed at room temperature during the oxidation of $\left[\mathrm{Cu}\left(\mathrm{H}_{2} \mathrm{~L}^{1}\right)_{2}\left(\mathrm{H}_{2} \mathrm{O}\right)\right]\left(\mathrm{ClO}_{4}\right)_{2}$ (1) with copper(II) perchlorate in acetonitrile. ${ }^{12}$ The formation and decay of the peak, however, could not be monitored at room temperature. The reaction was therefore monitored at $-20^{\circ} \mathrm{C}$, where a $\mathrm{CT}$ band was observed at $608 \mathrm{~nm}$. The CT band then decayed to a copper(II) complex $\left[\mathrm{Cu}\left(\mathrm{L}^{3}\right)_{2}\left(\mathrm{H}_{2} \mathrm{O}\right)\right]\left(\mathrm{ClO}_{4}\right)_{2}$ (2a) (figure 3). Note that, two equivalents of triethylamine were needed for the conversion of $\mathbf{1}$ to $\mathbf{2 a}$.

Similar spectroscopic feature of the intermediate was observed with a CT band at $615 \mathrm{~nm}$ when an acetonitrile solution of copper(II) perchlorate was added into a solution of $\left[\mathrm{Cu}(\mathrm{HDMG})_{2}\right]^{14}(\mathrm{HDMG}=$ monoanionic dimethylglyoximate) in acetonitrile at $-20^{\circ} \mathrm{C}$ (figure 4). Kinetic experiments established that at least three equivalents of copper(II) salt were required for maximum formation of the intermediate species. However, in the presence of other oxidizing agent like ceric ammonium nitrate, this oxidation process was observed to take place at $-20^{\circ} \mathrm{C}$ with the formation of a transient blue intermediate. This experiment ruled out the possibility of a metal cluster responsible for the blue colour of the intermediate. Additionally, the reaction of dimethylglyoxime with ceric ammonium nitrate alone failed to produce the blue intermediate species at low 


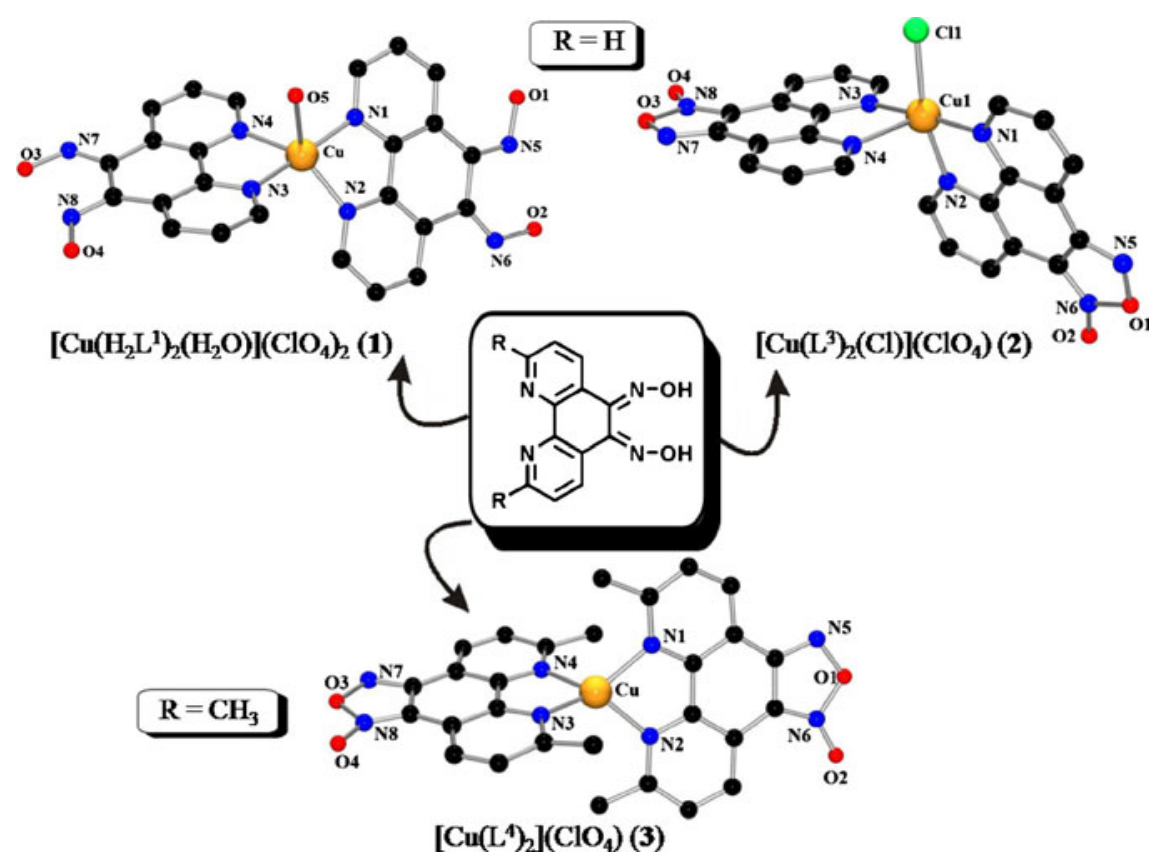

Figure 2. Copper complexes of 1,10-phenanthroline based dioximes and furoxans.

temperature. These observations suggested the intermediate species to be a copper(II) complex. It is important to mention that no solvent other than acetonitrile was able to carry out the oxidation reaction. The formation of furoxan from vic-dioximes under oxygen-free environment clearly points out that aerial oxygen does not participate in this electron transfer reaction.

X-band EPR spectrum of the blue intermediate species recorded at $123 \mathrm{~K}$ revealed four line hyperfine splitting of the parallel component with parameters typical for a mononuclear copper(II) species with axial

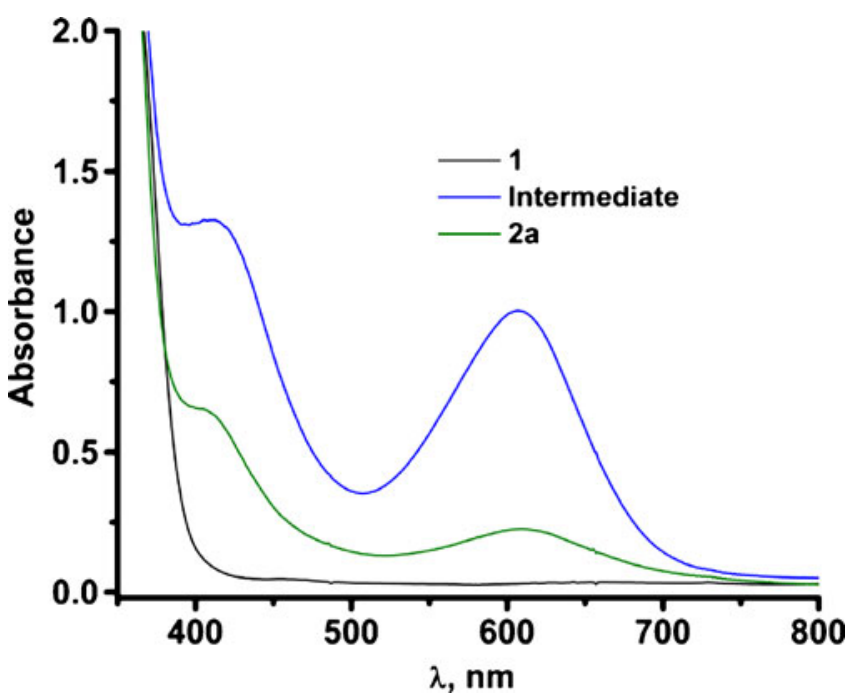

Figure 3. UV-Vis spectra of $\mathbf{1}, \mathbf{2}$ and the intermediate at $-20^{\circ} \mathrm{C}$ in acetonitrile (concentration: $0.25 \mathrm{mM}$ ). symmetry (figure 4, inset). The EPR parameters indicate the geometry of the copper centre to be a distorted tetrahedral in nature. ${ }^{15}$ The experimental results imply the presence of a two-electron oxidized ligand and a weaker equatorial bonding that results in the distortion from planarity. On the basis of these results, the transient blue intermediate was formulated as a mononuclear copper(II) complex coordinated by one dioximate and one two-electron oxidized form of dioximate.

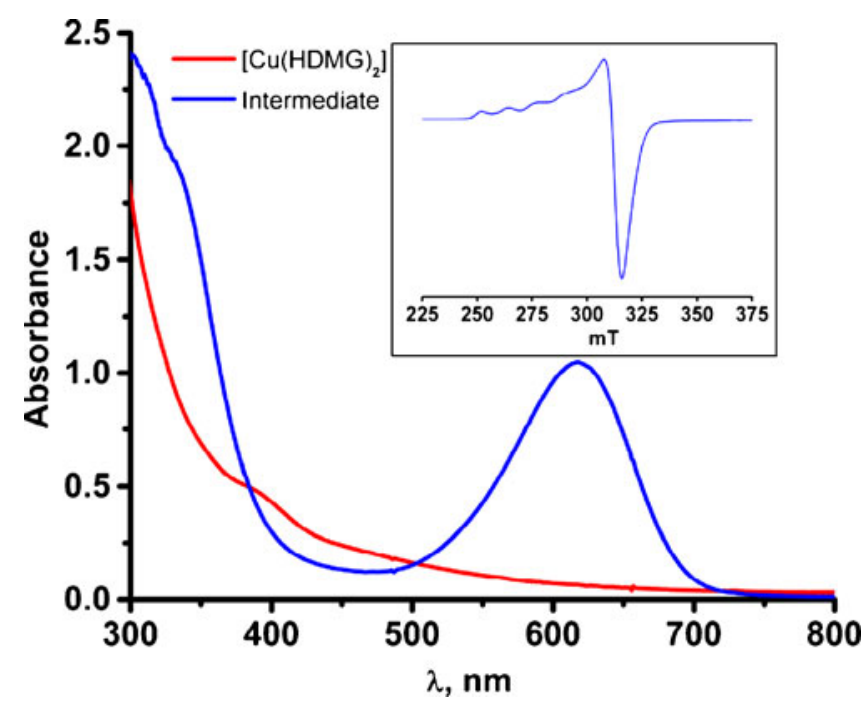

Figure 4. Optical spectrum of the blue intermediate formed in the reaction of $\left[\mathrm{Cu}(\mathrm{HDMG})_{2}\right]$ with copper(II) perchlorate at $-20^{\circ} \mathrm{C}$ in acetonitrile (concentration: $0.25 \mathrm{mM}$ ). Inset: EPR spectrum of the intermediate species at $123 \mathrm{~K}$. 


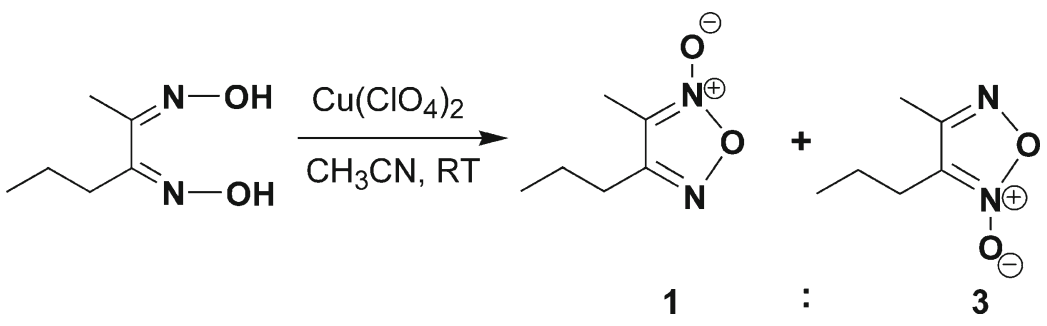

Scheme 3. Two different isomeric furoxans formed in the oxidation of hexane-2,3-dioxime.

Further evidence on the nature of the intermediate species was obtained from the oxidation of unsymmetrical vic-dioximes. The intermediate species formed during the oxidation of hexane 2,3-dioxime (showing CT band at $618 \mathrm{~nm}$ ) decayed to form two isomeric furoxans in a 3:1 ratio as determined by ${ }^{1} \mathrm{H}$ NMR spectroscopy (scheme 3). ${ }^{12}$ In this case, the two-electron oxidized ligand in the transient species cyclizes via two different pathways resulting in the formation of two isomeric furoxans. The stability of the oxidized ligand, which is affected by electronic factors of the substituents on vic-dioxime, controls the ratio of two isomers.

The effect of electronic factors on the stability of intermediate species has also been established with the 2,3-dioxime of acetoacetamide. ${ }^{16}$ The dioxime undergoes oxidative cyclization in the presence of copper(II) perchlorate in acetonitrile to afford only one furoxan A (scheme 4). It is expected that the other possible isomer (B) would get a better stability by hydrogen bonding interaction involving $\mathrm{NH}$ group of the amide moiety and the anionic oxygen of NO group. However, only one product from the oxidation of vic-dioxime of acetoacetamide indicates that the stability of intermediate species directs the cyclization pathway.

One of the coordinated dioximates in $\left[\mathrm{Cu}(\mathrm{HDMG})_{2}\right]$ gets oxidized by two electrons resulting in the formation of the blue intermediate. The two-electron oxidized form of oximate could be an iminoxyl diradical or an oxoimmonium cation. To get a better understanding on the intermediate species, the decay of the intermediate species was monitored by UV-Vis spectroscopy in the presence of different intercepting reagents like TEMPOH, 2,4,6-tri-tert-butylphenol and 3,5-di-tert- butylcatechol. Only 3,5-di-tert-butylcatechol was found to increase the rate of decay of the intermediate species by 10 times with subsequent formation of 3,5-ditert-butylquinone. ${ }^{12}$ The presence of radical quencher like TEMPOH or 2,4,6-tri-tert-butylphenol did not affect the decay of the intermediate species. All these experiments indicate the involvement of an oxoimmonium cation during the two-electron oxidation of vicdioximes. Oxoimmonium cation is a tautomeric form of neutral dinitrosoalkene that cyclizes to form furoxan (scheme 5). Dinitrosoalkenes are colourless and does not show any transition in the visible region. ${ }^{17}$

It has been proposed earlier that dinitrosoalkenes are short-lived intermediates in the isomerization of unsymmetrical furoxans. ${ }^{18-20}$ Moreover, dinitrosoalkenes are potential bidentate ligands and may coordinate to a copper(II) centre through two nitrogen donors. Therefore, the blue intermediate observed during the oxidation of vic-dioximes by copper(II) salts in acetonitrile may be formulated as a monomeric copper(II) centre coordinated by a dioximate ligand and dinitrosoalkene ligand (scheme 6). The oximate to dinitroso charge-transfer transition (ligand-to-ligand charge transfer transition) is responsible for the blue colour of the intermediate species. Copper(II) complexes supported by an electron-rich bidentate ligand and an electron-deficient bidentate acceptor ligand have been shown to exhibit such type of ligand-to-ligand charge transfer transition in the visible region. ${ }^{21}$ The blue intermediate then decays as a result of cyclization of the copper(II)-coordinated dinitrosoalkene or oxoimmonium cation to give two isomeric furoxans for unsymmetrical dioxime and a single furoxan for symmetrical dioxime (scheme 6).

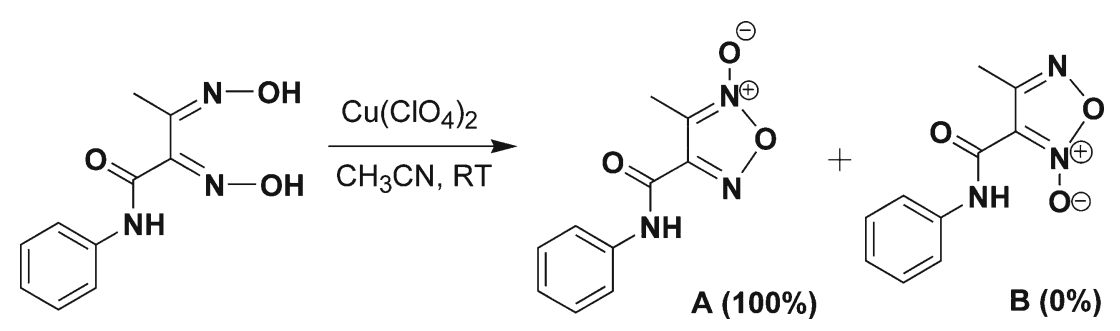

Scheme 4. Oxidation of the 2,3-dioxime of acetoacetamide. 


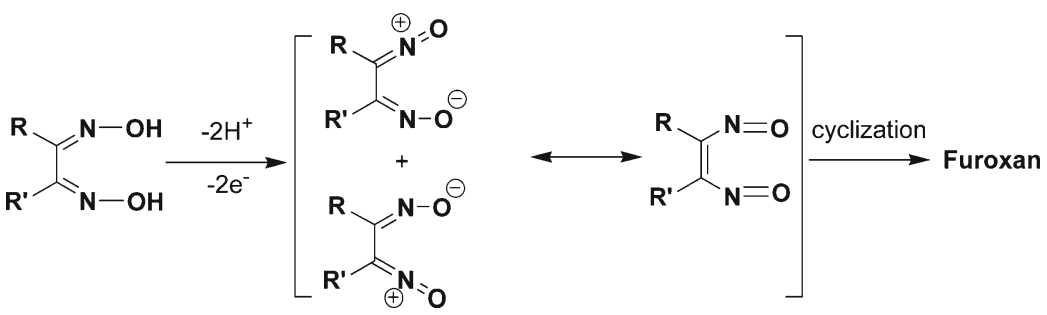

Scheme 5. Two-electron oxidized form of vic-dioxime.

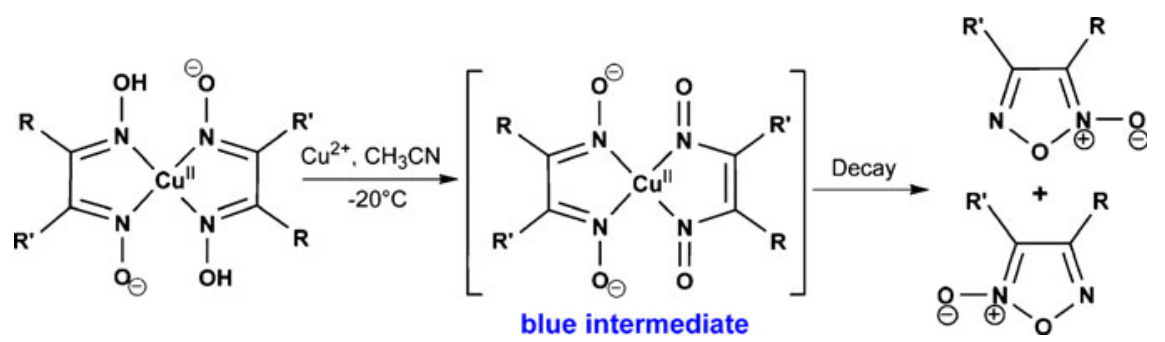

Scheme 6. Mechanistic proposal of the copper(II)-mediated oxidative cyclization of vic-dioximes.

\section{Conclusion}

The oxidation of vic-dioximes to furoxans using copper(II) perchlorate in acetonitrile under mild conditions has been discussed. The method has general applicability for a wide range of vic-dioxime substrates. Two copper complexes of 1,10-phenanthroline-based furoxans were isolated and structurally characterized. A dioximate-copper(II)-dinitrosoalkene species has been proposed as the transient intermediate in the twoelectron oxidative cyclization reaction. The involvement of a dinitrosoalkene species in the reaction mechanism was supported by the isolation of furoxans from the oxidation of unsymmetrical dioximes. The importance of metal ion in stabilizing the intermediate species in the oxidative transformation reaction has been documented.

\section{Acknowledgements}

This research was financially supported by the Department of Science and Technology (DST), Government of India.

\section{References}

1. Gasco A and Schoenafinger K 2005 In: Nitric oxide donors; P G Wang, T B Cai, N Taniguchi (eds); Weinheim: Wiley-VCH 131

2. Nirode $\mathrm{W}$ F, Luis J M, Wicker J F and Wachter N M 2006 Bioorg. Med. Chem. Lett. 16, 2299

3. Takayama H, Shirakawa S, Kitajima M, Aimi N, Yamaguchi K, Hanasaki Y, Ide T, Katsuora K, Fujiwara M, Ijichi K, Konno K, Sigeta S, Yokota T and Baba M 1996 Bioorg. Med. Chem. Lett. 61993
4. Cerecetto H, Di Maio R, Gonzáles M, Risso M, Saenz P, Seoane G, Denicola A, Peluffo G, Quijano C and OleaAzar C 1999 J. Med. Chem. 421941

5. Ghosh P B and Whitehouse M W 1969 J. Med. Chem. 12505

6. Sheremetev A B, Makhova N N and Friedrichsen W 2001 In: Advances in heterocyclic chemistry; A R Katritzky (ed); Academic Press: Amsterdam, Vol. 78, 66

7. Del Grosso E, Boschi D, Lazzarato L, Cena C, Di Stilo A, Fruttero R, Moro S and Gasco A 2005 Chem. Biodivers. 2886

8. Wang P G, Xian M, Tang X, Wu X, Wen Z, Cai T and Janczuk A 2002 J. Chem. Rev. 1021091

9. Takakis I M, Tsantali G G, Hass G W, Giblin D and Gross M L 1999 J. Mass Spectrom. 341137

10. Das O, Paria S and Paine T K 2008 Tetrahedron Lett. 49 5924

11. Niyazymbetov M E, Ul'yanova É V and Petrosyan V A 1990 Russ. Chem. Bull. 39551

12. Das O, Paria S, Zangrando E and Paine T K 2011 Inorg. Chem. 5011375

13. Britton D, Mallory F B and Mallory C W 2002 Acta Cryst. C58 o235

14. Ruiz R, Sanz J, Cervera B, Lloret F, Julve M, Bois C, Faus J and Muñoz M C 1993 J. Chem. Soc. Dalton Trans. 1623

15. Sakaguchi U and Addison A W 1979 J. Chem. Soc., Dalton Trans. 600

16. Das O, Sheet $D$ and Paine T K, unpublished result

17. Luzyanin K V, Gushchin P V, Pombeiro A J L, Haukka M, Ovcharenko V I and Kukushkin V Y 2008 Inorg. Chem. 476919

18. Gowenlock B G and Richter-Addo G B 2005 Chem. Soc. Rev. 34797

19. Mallory F B and Cammarata A 1966 J. Am. Chem. Soc. 8861

20. Bulacinski A B, Scriven E F V and Suschitzky H 1975 Tetrahedron Lett. 3577

21. Benedix R and Vogler A 1993 Inorg. Chim. Acta 204 189 